\title{
Tuberculosis Infection in Cattle and Cattle Owners in North Eastern Parts of Ethiopia
}

\author{
Araya Mengistu ${ }^{1 *}$, Fikre Enquselassie ${ }^{2}$, Fikrte Mulatu ${ }^{3}$ and Elena Hailu ${ }^{3}$ and Demissew Beyene ${ }^{3}$ \\ ${ }^{1}$ Faculty of Veterinary Medicine, University of Gondar, Gondar, Ethiopia \\ ${ }^{2}$ School of Public Health, College of Health Sciences, Addis Ababa University, Addis Ababa, Ethiopia \\ ${ }^{3}$ Armauer Hansen Research Institute, Addis Ababa, Ethiopia
}

\begin{abstract}
Introduction: Ethiopia is one of the highest TB burden countries in the world. Transmission of M. tuberculosis between humans is well known, however, little is known about the transmission of $M$. tuberculosis complex species between human and animals, in particular cattle. The purpose of this study was, therefore, to investigate the status of bovine tuberculosis infection in cattle owned by tuberculosis suspected households and isolate M. tuberculosis complex species from sputum of chronic coughers in North Wollo Zone of the Amhara National Regional State, Ethiopia.
\end{abstract}

Method: A cross-sectional study was conducted in selected Kebeles of North Wollo Zone. An intradermal tuberculin skin test was carried out on 381 cattle and sputum samples collected from 124 chronic coughers. Sputum samples were cultured and positive ones were identified by polymerase chain reaction using RD4 and RD9 as a marker.

Result: Of the 124 sputum samples cultured, 4/ 124 (3.2\%) were positive. Polymerase Chain Reaction using has confirmed that $2 / 4(50 \%)$ were found to be $M$. tuberculosis while the rest was atypical Mycobacterial species. Of the 381 tested cattle $5 / 381(1.31 \%)$ and $10 / 38(2.63 \%)$ were found positive according to manufacturer recommendation (with a cutoff value $>4 \mathrm{mms}$ ) and a cutoff value $>2 \mathrm{mms}$, respectively. About $67 \%(6 / 9)$ of the individuals who owned positive cattle were having the habit of drinking raw milk. Among the ten positives, five of them resided in lowland (Kolla) areas (1300-1500 mabs). However, none of the owners of tuberculin positive cattle were found to be TB positive.

Conclusion: This study has shown $3.2 \%$ of culture positivity and of these two were found to be $M$. tuberculosis. The sputum sample culturing from suspected chronically coughing individuals would help detection of the TB causative agents. According to the current findings BTB is considerable in Ethiopia and cattle should be seen as a potential source of zoonotic TB to humans.

Keywords: Bovine/cattle; Bovine tuberculosis; Cough; North Wollo; Skin test; Tuberculosis

\section{Introduction}

Human TB, caused by M. tuberculosis, is among the oldest diseases in the world and is the seventh leading cause of death worldwide [1]. WHO [2] reported that $98 \%$ of tuberculosis deaths occurred in the developing world, affecting mostly young adults in their productive ages. Despite efforts made, globally or nationally to curb the effects of TB, different studies have shown that the trend of pulmonary TB remained as a health problem in the world [3-7]. In 2013, WHO [8] reported a decline in the impact of tuberculosis by the year 2012. The challenge of TB is becoming complicated by the occurrence of HIV/ AIDS, the emergence of multi-drug resistant TB and extremely multidrug resistant and to some extent with totally multidrug resistant strains reported in some parts of the globe [9]. TB is still killing nearly 5000 people every day and 1.8 million deaths in 2008 alone [10]. If TB is left unchecked within 20 years, it will kill 35 million people [9].

Ethiopia ranks third in Africa, $8^{\text {th }}$ among the 22 highest TB burdened countries in the world and the prevalence of all forms of TB is estimated at 261 per 100000 population, leading to an annual mortality rate of 64 per 100000 population [11]. In 2008 the Amhara National Regional State Health Bureau reported 1.6\% and 3.5\% TB case detection and TB death rates, respectively [12]. The sources of infection for M.tuberculosis are mainly those humans who are developing active TB [13]. However, M.tuberculosis has been isolated from different animal species, including bovines/cattle, which should be seen as a challenge to further move in the prevention or controlling effort made to tackle the disease. In Ethiopia, little is known about the transmission of M.tuberculosis complex from cattle to humans. The purpose of this study is therefore, to investigate/determine the prevalence of BTB and see the possible role of cattle in the epidemiology of human TB and isolate Mycobacterium tuberculosis complex (MTC) species in North Wollo Zone, the Amhara National Regional State.

\section{Methodology}

\section{Study area}

This study was conducted in North Wollo Zone, Amhara National Regional State (ANRS). Woredas namely; Meket, Gidan, Gubalafto/ Woldeya and RayaKobo, were included in the study. The Kebeles comprised of lowland, mid-altitude and highlands. The Zone has a total population of 1,500,303 and a total of 355,974 households were counted and the cattle population was 836697 [14].

\section{Study design and study setting}

The study was Cross sectional and community based, which was

*Corresponding author: Araya Mengistu, Faculty of Veterinary Medicine University of Gondar, Gondar, Ethiopia, Tel: +251-0911752959; E-mail: armen. kassa@gmail.com

Received May 13, 2015; Accepted June 29, 2015; Published July 06, 2015

Citation: Mengistu A, Enquselassie F, Mulatu F, Hailu E, Beyene D (2015) Tuberculosis Infection in Cattle and Cattle Owners in North Eastern Parts of Ethiopia. Biol Med (Aligarh) 7: 241. doi: 10.4172/0974-8369.1000241

Copyright: (c) 2015 Mengistu A, et al. This is an open-access article distributed under the terms of the Creative Commons Attribution License, which permits unrestricted use, distribution, and reproduction in any medium, provided the original author and source are credited. 
conducted from December 5-24/2012.

\section{Study population, sampling method and sample size}

In this study, individuals suffering from chronic cough for a duration of two or more weeks were suspected as tuberculosis cases $[15,16]$. Sputum samples were collected from TB suspected individuals who own cattle and comparative cervical intradermal tuberculin test (CCITT) were conducted on their cattle. Single population proportion sample size determination was used, with the assumptions, prevalence of M. tuberculosis in herds recorded in Sudan [17,18] of 7.4\% with 3\% precision and $95 \%$ confidence interval. Based on this, 314 bovines were required to be tested. Gidan, Gubalafto, Rayakobo and Meket Woredas were selected purposefully and 314 cattle's were distributed proportional to sample size to each Woreda. Based on these 39, 79, 79 and 117 cattle were planned to be tested in Gidan (Eyela Kebele), Gubalafteo (Woynye and Sibilkay Kebeles), RayaKobo (Addis-alem and Robit area Kebeles) and Mekete (033 and 044 Kebeles) Woredas, respectively. Assuming an average of 3 cattle owned by a household in Amhara region, approximately 105 households were required to participate in the study. The seven Kebeles listed above (study sites), were selected based on the report having a high TB occurrence or being suspected to have TB by the local authorized personnel.

\section{Intradermal skin test on cattle}

Comparative cervical intradermal tuberculin test was conducted as manufacturer's recommendation [19]. The operation was performed on either side of the animal middle neck region. Two circular areas of about $2.5 \mathrm{~cm}$ diameter, about $12-15 \mathrm{~cm}$ apart, on the cervical area of the skin, were shaved using a scalpel blade. The initial skin thickness was measured with a digital caliper [20]. Measurements were read to the nearest millimeter. Lelystad (Netherlands) products of $0.1 \mathrm{ml}(20000$ $\mathrm{IU} / \mathrm{ml})$ of bovine tuberculin PPD at one site and $0.1 \mathrm{ml}(25000 \mathrm{IU} / \mathrm{ml})$ of avian tuberculin PPD at the other site were injected into the dermis using BD1/2 tuberculin syringe [21]. Correct injection was confirmed by palpating a small pea-like swelling at each site of injection. Skin thickness was measured again at both injection sites after $72 \mathrm{hrs} \pm 4 \mathrm{hrs}$. The reaction at each site was derived by calculating the difference of the two tests. The results were interpreted according to the manufacturer recommendations [19] using the cutoff point for positivity of the test, that is $>4 \mathrm{mms}$ difference, calculated as the difference between skin thicknesses of bovine tuberculin (B) and avian tuberculin (A) injection sites (B - A). But, Ameni et al. [22] reported $>2 \mathrm{~mm}$ difference as positive in Ethiopia. Based on his report, the test was considered positive if the difference was greater than $2 \mathrm{~mm}$.

\section{Cattle body weight estimation}

For the purpose of this study the method mentioned by Nicholson and Butterworth [23] with modifications was used to determine the body condition of the zebu cattle.

\section{Sputum sample collection and processing}

For M. tuberculosis isolation sputum samples were collected from individuals suffering from chronic cough, according to Cheesbrough [24]. Suspected cases were asked to produce an "on spot" sputum specimen in a $20 \mathrm{ml}$ screw plastic container under the supervision of a trained laboratory technician in the open air. Those cases who produced sputum were asked to give additional sputum samples on the second day and then on the spot. The sputum samples obtained from each patient was put in an ice box with ice packs $\left(4^{\circ} \mathrm{C}\right)$, and immediately after collection, it was transferred to the hospital laboratory to be stored at $-20^{\circ} \mathrm{C}$. The samples collected from each site transported to Armauer
Hansen Research Institute/AHRI TB laboratory to be processed.

Briefly, an equal amount of Phosphate-buffered saline solution was added to the sputum and then decontaminated, digested with equal volume of $4 \%$ sodium hydroxide for 15 minutes. Then vortaxing was done in a closed tube till the mixture becomes homogeneous. The homogenate was centrifuged at 3000 RPM for 15 minutes. Neutralization done by using concentrated hydrochloric acid. In order to monitor neutralization 1 or 2 drops of phenol red was added. The supernatant was decanted and the sediment was inoculated onto Lowenstein-Jensen medium (tubes containing glycerol and sodium pyruvate) using the drop method. The tubes were incubated at $37^{\circ} \mathrm{C}$ and examined for growth weekly for 12 weeks $[25,26]$. Cultures were considered negative if there was no mycobacteria growth after 12 weeks of incubation. Positive cultures were sub-cultured onto another set of media and incubated for another 3-4 weeks for further identification. Polymerase chain reaction using RD4 and RD9 as a marker was conducted. Armauer Hansen Research Institute (AHRI) M. tuberculosis $(H 37 R v)$ and M. bovis (AHRI No.1632) isolates used as a positive control.

\section{Data management, entry, analysis and data quality}

Good data management practices such as study monitoring, timely data archiving and transferring, sorting and filing were done. The collected data were coded and entered into EpiInfo version 3.2.1 [27]. Data cleaning and analysis were done by using SPSS software version 16.0 [28]. Descriptive statistics like frequency distributions, percentages, mean and standard deviations were used to describe the findings. Tables were used to present the results. The chi-square test was conducted to assess associations. All statistical tests were two-sided and significance was considered at a $p$-value $<0.05$. All data were collected in collaboration with experts and checked regularly while collecting the data by the principal investigator. All tuberculin tests were conducted by the same person and sputum sample collections and culturing done by laboratory personnel.

\section{Exclusion criteria}

Individuals having unproductive cough, less than 2 weeks duration of cough, those who have no cattle as well as under TB treatment and below 15 years were excluded. If sputum was not produced within 15 minutes he/she was exempted. Female cattle either recently delivered or at their last trimester, newly added, and those less than 6 months of old as well as aggressive cattle were not included in the study.

\section{Ethical considerations}

Ethical clearance was obtained from the college of health sciences, Addis Ababa University institutional review board (IRB) and AHRI/ ALERT (Armauer Hansen Research Institute) ethics committee. Permission was obtained from the Amhara Regional Health Bureau. The aim of the study was explained to the patient who was complaining chronic cough with one or more additional clinical signs and his/her willingness were asked to participate in the study. If he/she is willing to participate, consent were taken and sputum samples were collected. Confidentialities were maintained and to maintain confidentiality codes was used rather than participants' names. Based on the results individuals who own positive cattle were advised and those individuals whose sputum samples were cultured positives communicated through health institutes to receive appropriate treatments and conduct family screening. 


\section{Results}

The study covered Dega (highland) 3 (42.9\%), Woina Dega (midland) 3 (42.9\%) and Kolla (lowland) 1 (14.2\%) agroecological Zones. One hundred twenty four individuals (households) were reported to have a chronic cough in four words. Of the study participants, $76 \%$ were males Table 1.

The mean age of participants was $50(\underline{\underline{ \pm}} 15)$ and nearly one third of them aged between 40-50 years. The majority (nearly 60\%) of the individuals was having family size ranging from 1-5years age. About $92 \%$ of the participants reported to be followers of Orthodox Christianity. Of the participants about $69.4 \%$ were illiterate Table 1.

As it is presented in Table 2, among the participants, $17.3 \%$ and $15.3 \%$ had a TB history in their household and the patients were received antituberculosis treatment, respectively. Among the treated ones, only $15.3 \%$ completed a course of antituberculosis treatment. Chronic cough is not seen as a serious problem in the study area and hence nearly $77 \%$ of them were not taking any action and only $1 \%$ was seeking modern treatment for their ailments. Nearly $60 \%$ of the participants were suffering from chronic cough for more than 2 months. Nearly three fourth $(73.4 \%)$ and more than half (nearly $52 \%$ ) of the participants had the habit of taking unboiled milk and raw meat, respectively. Of the participants only $12 \%$ were having contact with TB diagnosed patients. Although there is no association all culture positive individuals were having the habit of taking unboiled milk as well as raw meat. From the collected 124 TB suspected sputum samples 4 Mycobacterial species, which accounted about $3.2 \%$, were grown in LJ media. Polymerase chain reaction using deletion method revealed that $2 / 4(50 \%)$ of the isolates were M. tuberculosis. Distribution of sputum culture positive results with some predictors is presented in Table 3.

As indicated in Table 3, all positive cultures (100\%) were belonging to males and out of which $2(50 \%)$ of them lived in the mid-altitude. Equal positive cultures were recorded in those who were illiterate and attending formal and informal education. Using the mean score (50yrs as a mean), three fourth of the culture positives where aged beyond 50 years. Besides, three fourth of the culture positives had a cough duration of more than 1 month and $75 \%$ of them took traditional treatments to curve cough situation. All culture positive individuals were not having a TB history in their house and there was no contact history. Polymerase Chain Reaction (PCR) using RD 9 as a marker indicated that 2 (50\%) among 4 sputum culture positives were $M$. tuberculosis while the rest were atypical Mycobacterial species.

Of the total participants who allowed their cattle to be tested $73.4 \%$ and $51.6 \%$ of them consumed unboiled milk and uncooked meat, respectively. In the actual work 381 cattle owned by these households were tested intra-dermal by using APPD (Avian purified protein derivative) and BPPD (Bovine purified protein derivative). Of the total cattle tested males contribute $192(50.4 \%)$. The mean age of cattle was $6.0341 \pm 3.5246$ and the majority of cattle $63.5 \%$ (almost two-third)

\begin{tabular}{|c|c|c|c|c|c|}
\hline \multicolumn{2}{|c|}{ Characteristics $(n=124)$} & \multirow{3}{*}{$\begin{array}{c}\text { No (\%) } \\
91(73.4) \\
33(26.6)\end{array}$} & \multicolumn{2}{|c|}{ Characteristics } & No (\%) \\
\hline \multirow{2}{*}{ Sex } & Male & & \multirow{2}{*}{ Religion } & Orthodox & $114(91.9)$ \\
\hline & Female & & & Muslim & $10(8.1)$ \\
\hline \multirow{5}{*}{ Age in years } & $18-28$ & $10(8.1)$ & \multirow{5}{*}{ Education } & Illiterate & $86(69.4)$ \\
\hline & $29-39$ & $19(15.3)$ & & Primary & $30(24.2)$ \\
\hline & $40-50$ & $37(29.8)$ & & Secondary & $4(3.2)$ \\
\hline & $51-61$ & $27(21.8)$ & & University & $1(0.8)$ \\
\hline & $>62$ & $31(25.0)$ & & Traditional & $3(2.4)$ \\
\hline
\end{tabular}

Table 1: Characteristics of TB suspected cases in North Wollo Zone, Ethiopia, 2012.

\begin{tabular}{|c|c|c|}
\hline \multicolumn{2}{|l|}{ Characteristics $(n=124)$} & No (\%) \\
\hline \multirow[t]{2}{*}{ Household TB history } & No & $102(82.3)$ \\
\hline & Yes & $22(17.7)$ \\
\hline \multirow[t]{2}{*}{ Receiving Treatment } & No treatment & $105(84.7)$ \\
\hline & Treated & $19(15.3)$ \\
\hline \multirow[t]{2}{*}{ Completing anti-TB Rx course } & Incomplete & $105(84.7)$ \\
\hline & Completed & $19(15.3)$ \\
\hline \multirow[t]{3}{*}{ Cough duration } & $\geq 2$ wks-1month & $37(29.8)$ \\
\hline & $>1$ month-2 months & $13(10.5)$ \\
\hline & $>2$ months & $74(59.7)$ \\
\hline \multirow[t]{3}{*}{ Action taken to combat cough } & No action & $95(76.6)$ \\
\hline & Modern & $1(0.8)$ \\
\hline & Traditional & $28(22.6)$ \\
\hline \multirow[t]{2}{*}{ Household contact with TB patient } & Yes & $109(88.0)$ \\
\hline & No & $15(12.0)$ \\
\hline \multirow[t]{4}{*}{ Feeding habit } & Drinking unboiled milk & $91(73.4)$ \\
\hline & Drinking boiled milk & $33(26.6)$ \\
\hline & Eating raw meat & $64(51.6)$ \\
\hline & Eating cooked meat & $60(48.4)$ \\
\hline \multirow[t]{2}{*}{ Sputum culture result } & Negative & $120(96.8)$ \\
\hline & Positive & $4(3.2)$ \\
\hline
\end{tabular}

Table 2: Tuberculosis history, feeding habit and sputum culture result of TB suspected cases in North Wollo Zone, Ethiopia, 2012. 
Citation: Mengistu A, Enquselassie F, Mulatu F, Hailu E, Beyene D (2015) Tuberculosis Infection in Cattle and Cattle Owners in North Eastern Parts of Ethiopia. Biol Med (Aligarh) 7: 241. doi: 10.4172/0974-8369.1000241

Page 4 of 7

\begin{tabular}{|c|c|c|c|}
\hline \multirow[b]{2}{*}{ Category } & \multirow{3}{*}{\begin{tabular}{|l|} 
Total \\
93
\end{tabular}} & \multicolumn{2}{|c|}{ Sputum culture results( $n=124)$} \\
\hline & & \multirow{2}{*}{\begin{tabular}{|l|} 
Positive (\%) \\
$4(3.2)$
\end{tabular}} & \multirow{2}{*}{\begin{tabular}{|l|} 
Negative (\%) \\
$89(71.8)$
\end{tabular}} \\
\hline Male & & & \\
\hline Female & 31 & $0(0)$ & $31(25.0)$ \\
\hline EcoZone & 55 & $1(0.8)$ & $54(43.5)$ \\
\hline Midland & 55 & $2(1.6)$ & $53(42.7)$ \\
\hline Lowland & 14 & $1(0.8)$ & $13(10.5)$ \\
\hline Education: & 86 & $2(1.6)$ & $84(67.8)$ \\
\hline Formal \& informal education & 38 & $2(1.6)$ & $36(29.0)$ \\
\hline Age (mean $=50 \pm 15)$ : & 68 & $1(0.8)$ & $67(54.1)$ \\
\hline Above the mean & 58 & $3(2.4)$ & $53(42.7)$ \\
\hline Cough duration: & 37 & $1(0.8)$ & $36(29.0)$ \\
\hline$>1$ month & 87 & $3(3.2)$ & $84(67.8)$ \\
\hline TB history in the household: No & 102 & $4(3.2)$ & $98(79.0)$ \\
\hline Yes & 22 & $0(0)$ & $22(17.8)$ \\
\hline Taking appropriate treatment $\quad$ No & 105 & $4(3.2)$ & $101(81.5)$ \\
\hline Yes & 19 & $0(0)$ & $19(15.3)$ \\
\hline Completing treatment course & 105 & $4(3.2)$ & $101(81.5)$ \\
\hline Yes & 19 & $0(0)$ & $19(15.3)$ \\
\hline Habit of drinking raw milk & 33 & $0(0)$ & $33(26.6)$ \\
\hline Yes & 91 & $4(3.2)$ & $87(70.2)$ \\
\hline Habit of taking raw meat: & 60 & $0(0)$ & $60(48.4)$ \\
\hline Yes & 64 & $4(3.2)$ & $60(48.4)$ \\
\hline Contact with TB patient: & 109 & $4(3.2)$ & $105(84.7)$ \\
\hline Yes & 15 & $0(0)$ & $15(12.1)$ \\
\hline
\end{tabular}

Table 3: Distribution of sputum culture positive results with some predictors, 2012.

\begin{tabular}{|c|c|c|c|c|}
\hline \multirow[b]{2}{*}{ Categories } & \multirow{3}{*}{$\begin{array}{c}\text { Cattle No (\%) } \\
365(95.8)\end{array}$} & \multicolumn{3}{|c|}{ Skin test result $(n=381)$} \\
\hline & & \multirow{2}{*}{$\begin{array}{c}\text { Positive }^{1} \text { No (\%) } \\
10(2.6)\end{array}$} & \multirow{2}{*}{$\begin{array}{c}\text { Negative }^{2} \text { No (\%) } \\
359(94.3)\end{array}$} & \multirow{2}{*}{$\begin{array}{c}\text { Inclusive }^{3} \text { No (\%) } \\
12(3.1)\end{array}$} \\
\hline Breed*: & & & & \\
\hline Cross & $16(4.2)$ & $0(0)$ & $0(0)$ & $0(0)$ \\
\hline Home-bred & $286(75.1)$ & $10(2.6)$ & $359(94.3)$ & $12(3.1)$ \\
\hline Purchase & $95(24.9)$ & $0(0)$ & $0(0)$ & $0(0)$ \\
\hline Sex : & $192(50.4)$ & $5(1.3)$ & $183(48.0)$ & $5(1.3)$ \\
\hline Female & $189(49.6)$ & $5(1.3)$ & $176(46.2)$ & $7(1.8)$ \\
\hline Body condition $^{* * *}$ : Lean & $65(17.1)$ & $0(0)$ & $66(18.4)$ & $0(0)$ \\
\hline Medium & $242(63.5)$ & $6(60)$ & $227(63.2)$ & $80(66.7)$ \\
\hline Fat & $74(19.4)$ & $4(40)$ & $66(18.2)$ & $4(33.3)$ \\
\hline EcoZone $^{* * * *}: \quad$ Dega $^{4}$ & $173(45.4)$ & $4(1.1)$ & $166(43.6)$ & $3(0.8)$ \\
\hline WoinaDega $^{5}$ & $151(39.6)$ & $1(0.3)$ & $148(38.9)$ & $2(0.6)$ \\
\hline Kolla ${ }^{6}$ & $57(15.0)$ & $5(1.3)$ & $45(11.8)$ & $7(1.8)$ \\
\hline
\end{tabular}

*: refers to indigenous zebu cattle and crosses of Holstein-Frisian in the study area

**: refers to the origin of cattle to the owner,

$* * *$ : indicates the nutritional status of cattle during the time of testing

****: indicates the three major agro-climatic Zones in North Wollo Zone

${ }^{1}$ differences in skin fold measurement greater than $2 \mathrm{mms}$; ${ }^{2}$ differences in skin fold measurement ranges between greater 1 mms- $<2$ mms; ${ }^{3}$ differences in skin fold measurement less than $1 \mathrm{mms}$

${ }^{4}$ Dega: equivalent to high land area; ${ }^{5}$ WoinaDega: Equivalent to Mid altitude; ${ }^{6} \mathrm{Kolla}$ : equivalent to low land

Table 4: Characteristics of tested cattle and skin test results in selected Kebeles of North Wollo Zone, Ethiopia, 2012.

were having medium body condition. Almost $96 \%$ of the cattle tested were local zebu and $75 \%$ of them were home-bred (Table 4 ).

Based on manufacturer recommendation [19] 5 (1.31\%) cattle were found positive. As it is shown in Table 4, according to previous cut off proved by Ameni et al. [22] of the tested cattle 10 (10/381) (2.63\%) were positive for the test. Highest positivity (with a reading $>4 \mathrm{mms}$ ) was recorded in Raya-Kobo Woreda, in Adis alem Kebele, where $5(\sim 8$. $8 \%)$ cattle revealed BTB out of 57 tested cattle. The total households in the Adisalem Kebele were 312, of which 14 households (4.5\%) were reported as having chronic cough and of these reactor cattle were recorded in four households, which is about $28.8 \%$. According to the manufacturer recommendation 12 (about 3.2\%) inconclusive test results were obtained. Of the positives females contribute $50 \%$ of skin test positivity. In general, according to Ameni et al. [22] report among the ten positive cattle, $4(40 \%), 1(10 \%)$ and $5(50 \%)$ cattle were positive for the test in Dega, Woina Dega and Kolla Woredas, respectively.

From the tested cattle nearly two-third (63.5\%), and among the positive once $60 \%$ of them were having medium body condition. Lean 
cattle did not show positive reaction. The majority of cattle (359/381), which accounted about $94.2 \%$, were negative for the test. Excluding inconclusive test result cattle, Fisher's exact test (Table 4) showed a significance difference $\left(\mathrm{P}<0.05, \chi^{2}=12.13\right.$ with $\left.2 \mathrm{df}\right)$ in skin test reaction among different agro-climatic Zones.

\section{Bovine tuberculosis}

According to the Purified Protein Derivative manufacturer's recommendation [19] from 381 tested cattle 5 of them showed positive results, in particular in Rayakobo Woreda, Addis-alem Kebele, which is characterized by kolla (equivalent to low land) agroclimatic Zone and this, contributes about $1.31 \%$. Based on this, the prevalence of BTB in this study was 0.013 (95\% CI, 1-03\%). In another scenario when the cut of skin fold measurements is taken as $>2 \mathrm{mms}$, according to Ameni et al., [22] the number of positive cattle recorded lifted to 10 , which in turn raises the prevalence to $2.63 \%$. Six (6/9, nearly $67 \%$ ) individuals among nine who owned positive cattle and reported having a chronic cough were having the habit of drinking unboiled milk.

\section{Discussion}

Although the role of M. bovis in human TB in Africa is not well known, its global contribution has been estimated about 3.1\% of all human TB cases [29]. But the agent is isolated in some African countries including Ethiopia from human sputum samples [30-43]. Reports made in countries like Egypt, Nigeria, Zaire and Tanzania confirmed bovine type human tuberculosis from their patients [44-47].

Of 124 sputum samples collected from chronic coughers 4 (3.2\%) culture positives ( 2 of them were M. tuberculosis based on PCR), were isolated. A tuberculosis survey conducted from October 2010June 2011 in Ethiopia, indicated $0.2 \%(110 / 51667)$ culture positivity from pulmonary TB suspected cases [48]. A study conducted in the rural community of South-west Ethiopia revealed a culture positivity of $\sim 4 \%(17 / 482)$ [49]. The current result lies within the limits of the two findings. The variability between these results might arise from differences in the quality of sputum sample, time of sputum sample collections, cold chain systems during collections and transportations as well as the time of processing after collection. Fifty percent of the isolates confirmed as atypical Mycobacterial species. As it is indicated in literature people could be infected with atypical Mycobacteria or Mycobacteria other than tuberculosis (MOTT) and some of them could lead to disease development in different parts of the body including the lungs [50].

Majorities suffered from a chronic cough for more than 2 months and more than three-fourth (77\%) of participants did not take any action to cure their cough as well as $75 \%$ of the culture positives had cough duration of more than 2 months. These factors will increase the chance of disease transmission; if the individual is infected with tuberculosis since smear negative-culture positive cases are responsible for $20 \%$ of tuberculosis transmission $[51,52]$. Three-fourth of the culture positive individuals were aged beyond 50 years old and this might be related to the decline in host immunity as age increases. Chain and colleagues 1995 [53] reported that immunologic abnormalities in elders led to tuberculosis development.

Among the coughing individuals, $74 \%$ (nearly three fourth) were having the habit of taking raw/unboiled milk. Taking unboiled/raw milk could be a potential source of infection to humans as described above since infected cows excrete M. bovis via milk [54]. Polymerase chain reaction conducted from Albanian milk samples in Tirana university revealed the presence of the MTC gene in 36/50 (72\%) of the tested samples would support the possibility of ingesting the disease causing agent [55].

In the current study, 381 cattle owned by chronic coughers were tested and prevalence of 2.63 was recorded. The prevalence of BTB in Meskanmareko, Woldeya, Bakogazer Woredas and Bale mountains was $7.9 \%, 1.2 \%, 4.3 \%$ and $2.0 \%$, respectively with an overall prevalence of $3.1 \%$ [56]. The prevalence in small scale dairy production systems ranges from $3.5 \%$ in Asella to $14.2 \%$ in Wolaita Sodo area $[57,58]$. The prevalence in intensive dairy farms ranged from $4.5 \%-73.6 \%$ in Desie area $[59,60]$, whereas in the traditional management system, it ranged from 3.4\% (West Wolega) to 22\% (Kombolcha) [59,61]. The present finding is a bit higher to the findings of Woldeya area, otherwise, it is in agreement with the overall findings reported by Tschopp et al. [56] and fall within the ranges of her findings. The difference in Woldeya area might be attributed to the time difference in conducting intradermal skin test, the area covered as well as the sampling techniques. The current finding difference from different management systems might be described to the differences in breed types/composition, the way of management of cattle, herd size, the environment and the body condition of the cattle during testing time, which is related to feed availability.

All cattle showed a positive result for the test was local zebu breed and $100 \%$ home-bred, having a longer contact period (with a mean age of $6.0341+3.5246$ ) to the household. Longer contact period might act as a source of infection to the family members as well as cattle including other animal species and at large to the community. As a result of longer duration of stay with the household, females, particularly lactating ones will serve as a permanent source of infection since it has been reported that a single cow can excrete sufficient viable mycobacteria in milk to make even pooled milk infective [54,64] and infection of the udder has been found in varying proportions of tuberculous animals as high as $5.4 \%[54,62]$.

The difference between Dega, WoinaDega and Kolla areas in BTB was significant $\left(\mathrm{P}<0.05, \chi^{2}=12.13\right.$ with $\left.2 \mathrm{df}\right)$. Report in Ethiopia indicated that the prevalence is relatively high in the highlands, having an altitude of $>2000$ masl [63]. Indeed the presence of difference in skin test positivity in geographical locations is described by another author [64]. However, this needs further study since altitude in human TB showed a higher TB prevalence in low altitudes [65,66]. Purposive sampling of the study areas, lack of a comparative study, focusing on chronic coughers as well as failure to resample negative chronic coughers could be seen as a limitation of this study.

\section{Conclusion and Recommendations}

Despite the current finding in this study looked small and lacked representativeness, the work can tell us the advantage of culturing since all of the culture positive chronic coughers were smear negatives. These culture positive ones are active pulmonary $\mathrm{TB}$ cases and hence the spread of the agent to the family or those who had/have contact with them is more likely. In this study four were found positive culture, of which half were atypical Mycobacteria. The finding of atypical Mycobacterial species in humans should be seen as a problem in the study areas. The presence of skin test positive cattle in different herds owned by different households should be seen as an indication as to the possible source of infection to humans, in particular zoonotic TB. In this study, more than two-third of the individuals suffered from chronic cough and owned positive cattle practiced consuming raw milk, whereby infected cows excrete the bacilli via milk chance of taking the BTB causative agent. A prevalence of $2.63 \%$ was recorded and those positive cattle might 
remain as a source of infection for the family, to the neighbors and at large to the community as well as to other animal species. Even though bovine $\mathrm{TB}$ was not found from culture positive chronic coughers, the current approach to see the BTB situation on their cattle owned by them will serve as a springboard for future possible cross infection assessment of Mycobacterial species to both populations.

Early detection of chronic coughers, identification of the causes of chronic cough, family members screening for $\mathrm{TB}$, treatment for active pulmonary $\mathrm{TB}$ cases, repeated sputum sample collection and processing for the chronic coughers as well as a means of exclusion or culling of positive cattle to break the possible cycles of BTB in the study area and continual community awareness with further research based on altitudes are recommended. Besides, to have a better picture as to the prevalence of the disease among individuals who suffered from chronic cough case control study is suggested.

\section{Competing Interests}

The authors have declared that they have no competing interests.

\section{Acknowledgements}

The authors would like to extend thanks to School of public health, AAU Armauer Hansen Research Institute (AHRI/ALERT), Gondar University, North Wollo Zone Health department as well as respective Woredas health offices and health centers, Gubalafto Woreda Agricultural and Rural Development Department, National Animal Health Research Institute, Kebele leaders and above all the participants.

\section{Financial support}

This study was supported by Addis Ababa University, Armauer Hansen Research Institute and University of Gondar.

\section{References}

1. Murray CJ, Salomon JA (1998) Modeling the impact of global tuberculosis control strategies. Proc Natl Acad Sci U S A 95: 13881-13886.

2. World Health Organization (WHO) (2005). Global burden of tuberculosis (Stop TB partnership).

3. Imam T, Oyeyi T (2008). Retrospective study of PTB prevalence among patients attending in infectious disease hospital. Bayero J pure app sci 1:10-15.

4. Lee LT, Chen CJ, Tsai SF, Suo J, Chen CY (1992) Morbidity and mortality trends of pulmonary tuberculosis in Taiwan. J Formos Med Assoc 91: 867-872.

5. Mor Z, Lerman Y, Leventhal A (2008) Pre-immigration screening process and pulmonary tuberculosis among Ethiopian migrants in Israel. Eur Respir J 32: 413-418.

6. Tessema B, Muche A, Bekele A, Reissig D, Emmrich F, et al. (2009) Treatment outcome of tuberculosis patients at Gondar University Teaching Hospital, Northwest Ethiopia. A five--year retrospective study. BMC Public Health 9: 371.

7. Ramos JM, Reyes F, Tesfamariam A (2010) Childhood and adult tuberculosis in a rural hospital in Southeast Ethiopia: a ten-year retrospective study. BMC Public Health 10: 215.

8. Global Tuberculosis Report (2013). World Health Organization, Geneva, Switzerland.

9. Velayati AA, Masjedi MR, Farnia P, Tabarsi P, Ghanavi J, et al. (2009) Emergence of new forms of totally drug-resistant tuberculosis bacilli: super extensively drug-resistant tuberculosis or totally drug-resistant strains in iran. Chest 136: 420-425.

10. Shukla S (2007). Critical Path to Tuberculosis Regimen: New Hope of Life for TB Patients. Media for freedomcom.

11. Regional office for Africa (2010-2013). World Health Organization, Geneva Switzerland

12. Tuberculosis annual report (2008). Health Bureau Amhara National Regional State (ANRS).

13. Tuberculosis (2008). American Lung Association Lung Disease, USA.
14. Central Statistics Agency, Census(2007). Amhara Region.

15. Masjedi MR, Tabatabaee D, Salak S (1997). Tuberculosis guide. IR Iran Foreign Minister Publish Cente, 64-65.

16. Modules of Tuberculosis Program (1995). World Health Organization (WHO), geneva, Switzerland

17. Ocepek M, Pate M, Zolnir-Dovc M, Poljak M (2005) Transmission of Mycobacterium tuberculosis from human to cattle. J Clin Microbiol 43: 35553557.

18. Boulahbal F, Benelmouffok A, Brahimi K (1978) [Role of Mycobacterium tuberculosis in bovine tuberculosis]. Arch Inst Pasteur Alger 53: 155-164.

19. Lelystad. Biological, Tuberculin PPD Kit. BV HL, Lelystad,Edelhertweg 15, $8219 \mathrm{P}$, The Netherlands.

20. Vernier caliper Manufactures \& Suppliers. 6" 150 mm Digital vernier caliper.

21. Becton. Dickinson and company. BD-1/2cc, tuberculin syringe, Precision glide permanently attached needle, $27 \mathrm{G} 1 / 2(0.040 \mathrm{~mm} \times 13 \mathrm{~mm})$, Franklinlakes. NJ 07417-1884.

22. Ameni G, Hewinson G, Aseffa A, Young D, Vordermeier M (2008) Appraisal of interpretation criteria for the comparative intradermal tuberculin test for diagnosis of tuberculosis in cattle in central Ethiopia. Clin Vaccine Immunol 15: $1272-1276$.

23. Nicholson MJ, Butterworth MH (1986). A guide to condition scoring of Zebu cattle. International Livestock Center for Africa, Addis Ababa. Ethiopia.

24. Cheesbrough M (1985). Medical Laboratory Manual for Tropical Countries. Microbiology, Uni Press, Cambridge 11: 294-297.

25. Cole ST, Barrell BG (1998) Analysis of the genome of Mycobacterium tuberculosis H37Rv. Novartis Found Symp 217: 160-172.

26. Tuberculosis (TB) Control and Prevention Program (2010). Virginia Department of health. Tuberculosis Epidemiology and Surveillance. USA

27. Epilnfo Version 3.2.1. 2014

28. Surur AS, Teni FS, Girmay G, Moges E, Tesfa M, et al. (2015) Assessment of the structural and process aspects of pharmaceutical care at a university hospital in Ethiopia. J Pharm Bioallied Sci 7: 97-102.

29. Cosivi O, Grange JM, Daborn CJ, Raviglione MC, Fujikura T, et al. (1998) Zoonotic tuberculosis due to Mycobacterium bovis in developing countries. Emerg Infect Dis 4: 59-70.

30. Niobe-Eyangoh SN, Kuaban C, Sorlin P, Cunin P, Thonnon J, et al. (2003) Genetic biodiversity of Mycobacterium tuberculosis complex strains from patients with pulmonary tuberculosis in Cameroon. J Clin Microbiol 41: 25472553

31. Koeck JL, Bernatas JJ, Gerome P, Fabre M, Houmed A, et al. (2002) [Epidemiology of resistance to antituberculosis drugs in Mycobacterium tuberculosis complex strains isolated from adenopathies in Djibouti. Prospective study carried out in 1999]. Med Trop (Mars) 62: 70-72.

32. Cooksey RC, Abbadi SH, Woodley CL, Sikes D, Wasfy M, et al. (2002) Characterization of Mycobacterium tuberculosis complex isolates from the cerebrospinal fluid of meningitis patients at six fever hospitals in Egypt. $\mathrm{J}$ Clin Microbiol 40: 1651-1655

33. Addo K1, Owusu-Darko K, Yeboah-Manu D, Caulley P, Minamikawa M, et al (2007) Mycobacterial species causing pulmonary tuberculosis at the korle bu teaching hospital, accra, ghana. Ghana Med J 41: 52-57.

34. Cadmus S, Palmer S, Okker M, Dale J, Gover K, et al. (2006) Molecular analysis of human and bovine tubercle bacilli from a local setting in Nigeria. $J$ Clin Microbiol 44: 29-34.

35. Mawak J, Gomwalk N, Bello C, Kandakai-Olukemi Y (2006) Human pulmonary infections with bovine and environment (atypical) mycobacteria in jos, Nigeria. Ghana Med J 40: 132-136.

36. Cleaveland S, Mlengeya T, Kazwala RR, Michel A, Kaare MT, et al. (2005) Tuberculosis in Tanzanian wildlife. J Wildl Dis 41: 446-453.

37. Kazwala RR, Daborn CJ, Kusiluka LJ, Jiwa SF, Sharp JM, et al. (1998) Isolation of Mycobacterium species from raw milk of pastoral cattle of the Southern Highlands of Tanzania. Trop Anim Health Prod 30: 233-239.

38. Mfinanga SG, Morkve O, Kazwala RR, Cleaveland S, Sharp MJ, et al. 
Citation: Mengistu A, Enquselassie F, Mulatu F, Hailu E, Beyene D (2015) Tuberculosis Infection in Cattle and Cattle Owners in North Eastern Parts of Ethiopia. Biol Med (Aligarh) 7: 241. doi: 10.4172/0974-8369.1000241

(2004) Mycobacterial adenitis: role of Mycobacterium bovis, non-tuberculous mycobacteria, HIV infection, and risk factors in Arusha, Tanzania. East Afr Med J 81: 171-178.

39. Asiimwe BB, Koivula T, Källenius G, Huard RC, Ghebremichael S, et al. (2008) Mycobacterium tuberculosis Uganda genotype is the predominant cause of TB in Kampala, Uganda. Int J Tuberc Lung Dis 12: 386-391.

40. Niemann S, Rüsch-Gerdes S, Joloba ML, Whalen CC, Guwatudde D, et al (2002) Mycobacterium africanum subtype II is associated with two distinct genotypes and is a major cause of human tuberculosis in Kampala, Uganda. J Clin Microbiol 40: 3398-3405

41. Oloya J, Opuda-Asibo J, Kazwala R, Demelash AB, Skjerve E, et al. (2008) Mycobacteria causing human cervical lymphadenitis in pastoral communities in the Karamoja region of Uganda. Epidemiol Infect 136: 636-643.

42. Morris RS, Pfeiffer DU, Jackson R (1994) The epidemiology of Mycobacterium bovis infections. Vet Microbiol 40: 153-177.

43. Fetene T, Kebede N, Alem G (2011) Tuberculosis infection in animal and human populations in three districts of Western Gojam, Ethiopia. Zoonoses Public Health 58: 47-53.

44. Nafeh MA, Medhat A, Abdul-Hameed AG, Ahmad YA, Rashwan NM, et al. (1992) Tuberculous peritonitis in Egypt: the value of laparoscopy in diagnosis. Am J Trop Med Hyg 47: 470-477.

45. Idigbe EO, Anyiwo CE, Onwujekwe DI (1986) Human pulmonary infections with bovine and atypical mycobacteria in Lagos, Nigeria. J Trop Med Hyg 89: 143148.

46. Mposhy M, Binemo Madi C, Mudakikwa B (1983). Incidence of bovine tuberculosis on the heath of the population of North Kivu (Zaire). J Animal Husbandry Veterinary Medicine tropical countries, 36: 15-18.

47. Daborn CJ, Grange JM, Kazwala RR (1996) The bovine tuberculosis cycle--an African perspective. Soc Appl Bacteriol Symp Ser 25: 27S-32S

48. Alebachew Z (2011). Ethiopian National TB Prevalence survey 2010 -2011 Preliminary Result. FMOH/EHNRI, Lille, France.

49. Deribew A, Abebe G, Apers L, Abdissa A, Deribe F, et al. (2012) Prevalence of pulmonary TB and spoligotype pattern of Mycobacterium tuberculosis among TB suspects in a rural community in Southwest Ethiopia. BMC Infect Dis 12: 54 .

50. Atypical mycobacteria. Nontuberculous mycobacteria, mycobacteria other than tuberculosis [mott]. Communicable disease epidemiology section P-42027 (Rev. 42005/42004). Wisconsin division of public health: Department of health services. Disease Fact Sheet Series, USA.

51. Behr MA, Warren SA, Salamon H, Hopewell PC, Ponce de Leon A, et al. (1999)
Transmission of Mycobacterium tuberculosis from patients smear-negative for acid-fast bacilli. Lancet 353: 444-449.

52. Hernández-Garduño E, Cook V, Kunimoto D, Elwood RK, Black WA, et al (2004) Transmission of tuberculosis from smear negative patients: a molecular epidemiology study. Thorax 59: 286-290.

53. Chan CH, Woo J, Or KK, Chan RC, Cheung W (1995) The effect of age on the presentation of patients with tuberculosis. Tuber Lung Dis 76: 290-294.

54. Kleenberg HH (1984). Human tuberculosis of bovine origin in relation to public health. Rev sci tech Off int Epiz 3:11-32.

55. Angela DP, Giuseppina C, Tony FV, Bijo B, Fatmira S, et al. (2006). Detection of Mycobacterium tuberculosis complex in milk using polymerase chain reaction (PCR). Food Control 17:776-780.

56. Tschopp R, Schelling E, Hattendorf J, Aseffa A, Zinsstag J (2009) Risk factors of bovine tuberculosis in cattle in rural livestock production systems of Ethiopia. Prev Vet Med 89: 205-211.

57. Alemayehu R (1999) Preliminary study on bovine tuberculosis in Walita Soddo Southern Ethiopia. DVM Thesis Faculty of Veterinary Medicine, Addis Ababa University Ethiopia.

58. Redi N (2003) Prevalence of bovine tuberculosis and zoonotic implication in Asela Town, South East Ethiopia. [DVM Thesis] Faculty of Veterinary Medicine,Addis Ababa University, Debre-Zeit, Ethiopia.

59. Tadele AD (1998) Evaluation of diagnostic tests, prevalence and zoonotic importance of BTB in Ethiopia. [DVM Thesis] Faculty of Veterinary Medicine, Addis Ababa University, Debre-Zeit, Ethiopia.

60. Ameni G, Bonnet P, Tibbo M (2003). A cross-sectional study of bovine tuberculosis in selected dairy farms in Ethiopia. Int J Appl Res Vet Med 1:85-97.

61. Regassa F (2001). Herd prevalence of CBPP and BTB and Dictyocaulosis in Bodji Wereda in West Wellega. [DVM Thesis] Faculty of Veterinary Medicine, AddisAbaba University, Debre-Zeit, Ethiopia.

62. Sharma AK, Vanamayya PR, Parihar NS (1985). Tuberculosis in cattle: a retrospective study based on necropsy. Indian J vet Pathol 9:14-18.

63. Tschopp R, Berg S, Argaw K, Gadisa E, Habtamu M, et al. (2010). Bovine tuberculosis in Ethiopian wildlife. J Wildl Dis 46: 753-762

64. Phillips CJ, Foster CR, Morris PA, Teverson R (2002) Genetic and management factors that influence the susceptibility of cattle to Mycobacterium bovis infection. Anim Health Res Rev 3: 3-13.

65. Vargas MH, Furuya ME, Pérez-Guzmán C (2004) Effect of altitude on the frequency of pulmonary tuberculosis. Int J Tuberc Lung Dis 8: 1321-1324.

66. Saito M, Pan WK, Gilman RH, Bautista CT, Bamrah S, et al. (2006) Comparison of altitude effect on Mycobacterium tuberculosis infection between rural and urban communities in Peru. Am J Trop Med Hyg 75: 49-54. 